\title{
Unil
}

UNIL | Université de Lausanne

Unicentre

$\mathrm{CH}-1015$ Lausanne

http://serval.unil.ch

Year : 2018

\section{Clinical signs of hypoxaemia in children aged 2 months to 5 years with acute respiratory dîstress in Switzerland and Senegal}

\author{
Von Der Weid Lucie
}

Von Der Weid Lucie, 2018, Clinical signs of hypoxaemia in children aged 2 months to 5 years with acute respiratory dîstress in Switzerland and Senegal

Originally published at : Thesis, University of Lausanne

Posted at the University of Lausanne Open Archive http://serval.unil.ch

Document URN : urn:nbn:ch:serval-BIB_F7F3AD6E31407

\section{Droits d'auteur}

L'Université de Lausanne attire expressément l'attention des utilisateurs sur le fait que tous les documents publiés dans I'Archive SERVAL sont protégés par le droit d'auteur, conformément à la loi fédérale sur le droit d'auteur et les droits voisins (LDA). A ce titre, il est indispensable d'obtenir le consentement préalable de l'auteur et/ou de l'éditeur avant toute utilisation d'une oeuvre ou d'une partie d'une oeuvre ne relevant pas d'une utilisation à des fins personnelles au sens de la LDA (art. 19, al. 1 lettre a). A défaut, tout contrevenant s'expose aux sanctions prévues par cette loi. Nous déclinons toute responsabilité en la matière.

\section{Copyright}

The University of Lausanne expressly draws the attention of users to the fact that all documents published in the SERVAL Archive are protected by copyright in accordance with federal law on copyright and similar rights (LDA). Accordingly it is indispensable to obtain prior consent from the author and/or publisher before any use of a work or part of a work for purposes other than personal use within the meaning of LDA (art. 19, para. 1 letter a). Failure to do so will expose offenders to the sanctions laid down by this law. We accept no liability in this respect. 


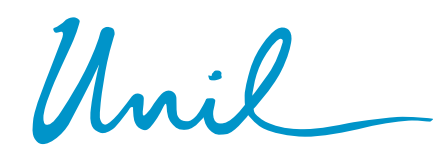

UNIL | Université de Lausanne

\title{
Ecole doctorale
}

UNIVERSITÉ DE LAUSANNE - FACULTÉ DE BIOLOGIE ET DE MÉDECINE

Département Femme-Mère-Enfant

Service de pédiatrie

\section{Clinical signs of hypoxaemia in children aged 2 months to 5 years with acute respiratory distress in Switzerland and Senegal}

\author{
THESE
}

préparée sous la direction du Docteur Mario Gehri

et présentée à la Faculté de biologie et de médecine de

I'Université de Lausanne pour I'obtention du grade de

DOCTEUR EN MEDECINE

par

Lucie von der Weid

Médecin diplômée de la Confédération Suisse

Originaire de Fribourg 


\section{Unil}

UNIL | Université de Lausanne

Faculté de biologie et de médecine

Ecole Doctorale Doctorat en médecine

\section{Imprimatur}

Vu le rapport présenté par le jury d'examen, composé de

Directeur de thèse Monsieur le Docteur Mario Gehri

Co-Directeur de thèse

Expert

Monsieur le Professeur Umberto Simeoni

Vice-Directeur de

Monsieur le Professeur John Prior

l'Ecole doctorale

la Commission MD de l'Ecole doctorale autorise l'impression de la thèse de

Madame Lucie VON DER WEID

intitulée

Clinical signs of hypoxaemia in children aged 2 months to 5 years with acute respiratory distress in Switzerland and Senegal

Lausanne, le 14 novembre 2017

pour Le Doyen

de la Faculté de Biologie et de Médecine

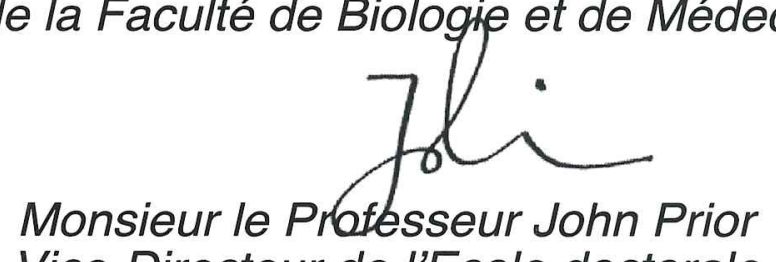

Vice-Directeur de l'Ecole doctorale 


\section{Résumé de thèse}

\section{Contexte}

L'hypoxémie est un facteur important de mortalité chez les enfants atteints de pneumonie. L'OMS a publié des recommandations pour l'oxygénothérapie en se basant sur les signes cliniques, pour les situations où il n'y pas de saturomètre disponible. Ces recommandations indiquent que, lorsque les réserves en oxygène sont suffisantes, l'oxygène concentré doit être donnée aux enfants qui présentent une cyanose centrale, sont incapables de boire, présentent une détresse respiratoire sévère, une respiration $\geq 70$ respirations par minute, un gémissement expiratoire (" grunting » en anglais) ou un signe de la tortue (" head nodding »). Ces recommandations ne sont cependant basées que sur peu d'études et doivent encore être validées.

\section{But}

Le but de cette étude est d'évaluer la performance diagnostique de plusieurs combinaisons de signes prédictifs d'hypoxémie, chez l'enfant âgé de deux mois à cinq ans avec une détresse respiratoire aiguë qui se présente aux urgences.

\section{Méthodes}

Cette étude observationnelle a été menée dans quatre centres d'urgences : deux en Suisse et deux au Sénégal. Les patients âgés de deux mois à cinq ans avec une détresse respiratoire aiguë pouvaient être inclus. Les signes cliniques étaient comparés au niveau de saturation sanguine transcutanée en oxygène $\left(\mathrm{SaO}_{2}\right)$.

\section{Résultats}

Un total de 111 enfants a été inclu, 67 en Suisse et 44 au Sénégal. La prévalence de l'hypoxémie était de 13\%. Douze modèles de combinaisons de symptômes ont été analysés. Le modèle de l'OMS pour les situations où les ressources en oxygène sont suffisantes a eu la meilleure performance diagnostique, avec une sensibilité de 93\% et une spécificité de 60\%.

\section{Conclusions}

Les signes cliniques ne permettent pas seuls de détecter une hypoxie. Le modèle actuel de l'OMS pour les situations où les ressources en oxygène sont suffisantes est le meilleur modèle prédictif, mais un grand nombre d'enfants non-hypoxémiques sont traités inutilement à cause du manque de spécificité de ce modèle.

\section{Perspectives}

Au vu du manque de spécificité de ce modèle, plus d'études sont nécessaires pour élaborer et valider des combinaisons de signes plus efficaces pour prédire l'hypoxémie chez les enfants. Nous suggérons que ces nouveaux modèles incluent des signes avec une haute performance diagnostique comme la cyanose, mais aussi les tirages subcostaux et intercostaux, l'état d'alerte altéré et le balancement thoraco-abdominal. 


\section{Clinical signs of hypoxaemia in children aged 2 months to 5 years with acute respiratory distress in Switzerland and Senegal}

Lucie von der Weid, Mario Gehri, Boubacar Camara, Aliou Thiongane, Andrès Pascual \& Jean-Yves Pauchard

To cite this article: Lucie von der Weid, Mario Gehri, Boubacar Camara, Aliou Thiongane, Andrès Pascual \& Jean-Yves Pauchard (2017): Clinical signs of hypoxaemia in children aged 2 months to 5 years with acute respiratory distress in Switzerland and Senegal, Paediatrics and International Child Health, DOI: 10.1080/20469047.2017.1390828

To link to this article: http://dx.doi.org/10.1080/20469047.2017.1390828

Published online: 06 Nov 2017.

Submit your article to this journal $\sqsubset$

View related articles $₫$

View Crossmark data ¿ 


\title{
Clinical signs of hypoxaemia in children aged 2 months to 5 years with acute respiratory distress in Switzerland and Senegal
}

\author{
Lucie von der Weid ${ }^{a, b}$, Mario Gehria, Boubacar Camara ${ }^{b}$, Aliou Thiongane ${ }^{c}$, Andrès Pascual ${ }^{d}$ and Jean- \\ Yves Pauchard ${ }^{\mathrm{a}}$
}

aHôpital de l'Enfance de Lausanne, Lausanne, Switzerland; ${ }^{b} \mathrm{CHN}$ de Pikine, Dakar, Senegal; 'CHU Albert-Royer, Dakar, Senegal; ${ }^{\mathrm{d} S e r v i c e}$ de Pédiatrie, Hôpital de Nyon, Nyon, Switzerland

\begin{abstract}
Background: Hypoxaemia is a predictor of pneumonia-related mortality. WHO published recommendations for oxygen therapy based on clinical signs which state that, when oxygen is plentiful, it should be given to children with central cyanosis, inability to drink, severe chest indrawing, RR $>70$ breaths/min, grunting with every breath (in young infants) or those who display head nodding. These guidelines, however, are based on a few studies only.

Aim: To assess the accuracy of combinations of clinical signs which predict hypoxaemia in pre-school children aged 2 months to 5 years with acute respiratory distress in hospitals in Switzerland and Senegal.

Methods: This observational study was conducted in four emergency units, two in Switzerland and two in Senegal. Patients aged 2 months to 5 years with acute respiratory distress were eligible for inclusion. Clinical signs were compared with transcutaneous blood saturation levels $\left(\mathrm{SaO}_{2}\right)$.

Results: About 111 children were assessed, 67 in Switzerland and 44 in Senegal. The prevalence of hypoxaemia was $13 \%$. Twelve models of combined symptoms were analysed. The WHO model, for when oxygen supply is ample, had the highest diagnostic performance with a sensitivity of 0.93 and a specificity of 0.60 .

Conclusions: Clinical signs alone are unreliable for the detection of hypoxaemia. The current WHO model, for ample oxygen supply proved to be the best clinical predictor, although a great number of non-hypoxaemic children were unnecessarily treated because of the low specificity of this model.
\end{abstract}

\section{ARTICLE HISTORY}

Received 27 June 2017 Accepted 3 October 2017

\section{KEYWORDS}

Hypoxaemia; acute respiratory distress; under-5

children; pulse oximetry clinical signs; diagnostic accuracy

\section{Introduction}

In low- and middle-income countries (LMIC), respiratory infections are one of the leading causes of morbidity and mortality in children under 5 years of age [1]. Hypoxaemia is an important predictor of pneumonia-related mortality [2]. Oxygen delivery to hypoxaemic children improves disease outcome $[3,4]$; however, the availability of concentrated oxygen is limited in LMIC. Pulse oximetry is a non-invasive and reliable method of detecting hypoxaemia by measuring arterial haemoglobin oxygen saturation $\left(\mathrm{SaO}_{2}\right)$ [5], proving to be better than clinical evaluation, but it is not widely available in resource-poor settings. In the absence of pulse oximetry, physicians must rely on clinical signs to decide whether oxygen therapy is required. In 2005, WHO published recommendations for oxygen therapy in children with acute respiratory infections [6]. They state that, when oxygen is limited, priority should be given to children with very severe pneumonia, bronchiolitis or asthma and those with central cyanosis, or who are unable to drink because of respiratory distress. When the oxygen supply is more plentiful, it should also be given to children with severe chest indrawing, respiratory rate $\geq 70$ breaths/min, grunting with every breath (in young infants) or who display head nodding [6]. However, these guidelines are mostly empirical. A meta-analysis undertaken in 2011 [7] found only 11 studies conducted in the previous 60 years which assessed clinical signs of hypoxaemia in children with acute respiratory infections. The authors concluded that there was a need for further prospective studies in primary care settings in low-income countries. In previous studies, many authors have attempted to determine models of clinical signs to improve the accuracy of the clinical diagnosis of hypoxaemia, but these models still need to be validated. This observational study was undertaken to investigate combinations of signs of hypoxaemia by comparing clinical signs and the level of blood oxygen saturation in children aged 2 months 
to 5 years presenting with acute respiratory distress in different emergency units in a resource-limited country (Senegal) and a resource-rich country (Switzerland).

\section{Patients and methods}

\section{Site and study period}

This study was conducted in the emergency unit of four hospitals from December 2015 until June 2016. Two of the hospitals were in Senegal: Pikine, a non-specialised hospital in a township of Dakar and in Hôpital pour Enfants Albert-Royer, de Dakar, HEAR, which is the national reference centre. Both are at sea level. In Switzerland, the study was undertaken in Groupement Hospitalier de I'Ouest Lémanique, GHOL, a regional hospital in Nyon and in Hôpital de l'Enfance de Lausanne, HEL, one of five paediatric reference centres in Switzerland. Both hospitals are 400-500 m above sea level. Both HEAR and HEL have specialised paediatric emergency units.

Children with acute respiratory distress who fulfilled the inclusion criteria and for whom informed consent was granted were enrolled.

\section{Inclusion criteria}

Patients were eligible for the study if they were aged between 2 months and 5 years and presented with acute respiratory distress, defined by at least one of the following clinical signs: tachypnoea, nasal flaring, chest retractions or respiratory sounds (stridor, wheezing, grunting) [8].

\section{Exclusion criteria}

Patients were excluded if they had signs of an obvious cardiac disorder (heart murmur, signs of cardiac insufficiency) or were known to have a cardiac disorder or a congenital pulmonary malformation.

\section{Study design}

The physicians evaluated the presence or absence of the specified clinical signs and reported them in a questionnaire as binary variables (present/absent). The vital signs were taken after the first medical evaluation. The transcutaneous blood saturation and the pulse rate were measured by a Nellcor ${ }^{\mathrm{TM}}$ Portable $\mathrm{SPO}_{2}$ Patient Monitoring System (model PM10N) with the pulse oximeter placed on the middle finger and measured values were interpreted after $2 \mathrm{~min}$ of a stable value. The respiratory rate was assessed by visual observation for $1 \mathrm{~min}$. No follow-up was undertaken in this study.

\section{Definition}

Hypoxaemia was defined as the transcutaneous oxygen saturation measured by the pulse oximetry when $\leq 90 \%$.

\section{Data collection}

Date of birth, diagnosis, vital signs (respiratory rate, pulse rate, transcutaneous blood saturation and temperature) and clinical signs were recorded. Clinical signs included neurological signs and respiratory function. They were evaluated at the first assessment by a medical officer. The neurological signs included poor general status (subjective opinion about the patient), abnormal alertness (impaired consciousness level), agitation and inability to drink (tested during the consultation). The respiratory signs included central cyanosis, grunting, nasal flaring, head nodding, chest retractions (supraclavicular, intercostal and subcostal), paradoxical breathing, crackles during auscultation, wheeze during auscultation and wheezing (musical noise heard without a stethoscope). The description of each sign was written in the questionnaire [8]. One clinician per site was responsible for data collection.

\section{Data management and statistical analysis}

All study questionnaires were entered in Microsoft Excel 2011. Statistical analysis was performed using Microsoft Excel and Epi Info. Univariate and multivariate logistic regression analyses were performed to assess associations between signs. Sensitivity, specificity, positive and negative likelihood ratio, diagnostic odds ratio and adjusted diagnostic odds ratio were calculated for all signs and for the 12 combinations of signs described in the meta-analysis [7]. About 95\% confidence intervals are presented.

\section{Ethical considerations}

This study was approved by the Cantonal Commission of Research Ethics in Humans (Commission Cantonale d'Ethique de la Recherche sur l'Etre Humain CER-VD, P 456/15) in Switzerland and by the medical chief of the Department of Paediatrics, Dakar. Oral informed consent was obtained from parents or guardians in French or a local language.

\section{Results}

\section{General overview}

During the study period, 111 children were assessed, 67 in Switzerland and 42 in Senegal. The mean age was 1 year 11 months (range 2 months to 4 years 11 months), $34(30 \%)$ of whom were infants and $74(66 \%)$ were male. Table 1 compares the prevalence and aetiology of hypoxaemia in each site. Table 2 shows the prevalence of obstructive airway disease and other aetiologies of acute respiratory distress in hypoxaemic and non-hypoxaemic patients. The hypoxaemia prevalence in patients with obstructive airways disease was $10 \%$ and in patients with parenchymatous or systemic diseases $21 \%$. 
Table 1. Descriptive data for study subjects by centre.

\begin{tabular}{|c|c|c|c|c|c|}
\hline Characteristics & HEL & Nyon & HEAR & Pikine & Total \\
\hline Patients (\% of total) & $29(26.1)$ & $38(34.2)$ & $37(33.3)$ & $7(6.3)$ & $111(100)$ \\
\hline Mean age, mths (SD) & $28.6(14.3-42.9)$ & $22.7(5.7-39.7)$ & $22.4(5.2-39.6)$ & $20.2(7.2-33.3)$ & $24(7.7-40.3)$ \\
\hline $\begin{array}{l}\text { Obstructive airways } \\
\text { diseases (\% by site) }\end{array}$ & $26(89.7)$ & $34(89.5)$ & $19(51.4)$ & $3(42.8)$ & $82(73.8)$ \\
\hline $\begin{array}{l}\text { Parenchymal diseases } \\
\text { (\% by site) }\end{array}$ & $3(1)$ & $2(0.5)$ & $15(40.5)$ & $3(42.8)$ & $23(20.7)$ \\
\hline $\begin{array}{l}\text { Systemic diseases } \\
\text { (\% by site) }\end{array}$ & 0 & $1(2.6)$ & $3(8.1)$ & $1(14.2)$ & $5(4.5)$ \\
\hline Hypoxaemia (\% by site) & $6(20.6)$ & $1(2.6)$ & $3(8.1)$ & $4(57.1)$ & $14(12.6)$ \\
\hline
\end{tabular}

Notes: HEL, Hôpital de l'Enfance de Lausanne, Switzerland; Nyon, Hôpital de Nyon, Department of Paediatrics, Switzerland; Pikine, Hôpital de Pikine, Department of Paediatrics, Senegal; HEAR, Hôpital pour Enfants Albert-Royer, Dakar, Senegal; obstructive airways diseases: bronchiolitis, obstructive bronchitis, asthma, croup and nasal obstruction; parenchymal diseases: pneumonia, pleural effusion and tuberculosis; systemic diseases: sepsis, septic shock, dehydration.

\section{Combination of clinical signs associated with hypoxaemia}

Sensitivity and specificity. Twelve models of combined symptoms were analysed [9-13]: four models, including the WHO model when oxygen supply is ample [6] and three models created by Lodha et al. [13], had a high sensitivity of 0.93 (0.88-0.98). The WHO model for when oxygen supply is ample had the best specificity of 0.60 (0.51-0.69) when compared with the three models of Lodha et al.

Three other models had a relatively high specificity: Dyke et al. with $0.86(0.79-0.92)$ [11], Usen et al. with 0.77 (0.70-0.84) [12] and the WHO model for when oxygen supply is scarce with $0.75(0.67-0.83)$ [6]. The WHO model had the best sensitivity of $0.75(0.67-0.83)$.

Positive and negative likelihood ratios, diagnostic odds ratio and adjusted diagnostic odds ratio. None of the models had a positive likelihood ratio higher than five which is the minimum to define a good clinical test. The WHO model for ample oxygen supply with its negative likelihood ratio of $0.12(0.02-0.80)$ was the only model with a negative likelihood ratio close to 0.1 (the cutoff for clinical tests). With regard to the diagnostic odds ratio (DOR), the WHO model for ample oxygen supply had the best diagnostic performance with a DOR of 19.33 (2.43-153.8), followed by the WHO model for scarce oxygen supply with a DOR of 11.15 (2.8743.34). Tables 3 and 4 show the prevalence, sensitivity, specificity and diagnostic odds ratios for each sign and combination of signs. Sensitivity and specificity are graphically represented in Appendices 1 and 2. Positive and negative likelihood ratios are listed in Appendices 3 and 4.

\section{Discussion}

The best model in terms of sensitivity and reasonable specificity is the WHO model for when oxygen supply is ample [6]: it has a diagnostic odds ratio of 19.33 and a negative likelihood ratio of 0.1 . This means that a child without any signs described by the model (cyanosis,
Table 2. Diagnosis in children aged 2 months to 5 years with acute respiratory distress, proportion of hypoxaemia.

\begin{tabular}{lcc}
\hline Diagnosis & Hypoxaemia & Normoxaemia \\
\hline No. of patients (\% of total) & $14(12.6)$ & $97(87.4)$ \\
$\begin{array}{l}\text { No. of obstructive airways diseases } \\
\text { (\% of hypo/normoxaemia) }\end{array}$ & $8(57.1)$ & $74(76.3)$ \\
$\begin{array}{l}\text { No. of parenchymatous or systemic } \\
\text { diseases (\% of hypo/normoxae- }\end{array}$ & $6(42.8)$ & $23(23.7)$ \\
mia) & & \\
\hline
\end{tabular}

Notes: Obstructive airways diseases: bronchiolitis, obstructive bronchitis, asthma, croup and nasal obstruction; parenchymal diseases: pneumonia, pleural effusion and tuberculosis; systemic diseases: sepsis, septic shock, dehydration.

inability to drink, severe chest in drawing, respiratory rate $\geq 70 / \mathrm{min}$, restlessness or grunting) is very probably not hypoxaemic. In Fagan's nomogram, a child with a pre-test probability of $40 \%$ (median hypoxaemia prevalence in previous studies conducted in resource-limited countries) [14-21] has a post-test probability of $5 \%$ if presenting with none of the signs included in the model. To conclude, almost all hypoxaemic children would be treated. Unfortunately, many non-hypoxaemic children would receive oxygen also because of the lack of specificity.

The model with the best specificity is the WHO model for scarce oxygen supply. It states that oxygen should be given to children with central cyanosis or inability to drink or feed. But, with a positive likelihood ratio of only 3.18 , this model is not sufficiently accurate for the diagnosis of hypoxaemia. Moreover, its use would lead to an unacceptably high number of hypoxaemic patients not receiving oxygen therapy because of its lack of sensitivity.

The mean age ( 1 year 11 months) was almost the same in all centres. The hypoxaemia prevalence varied greatly (3-57\%) between the four hospitals owing to population differences between the regions. However, the average prevalence (13\%) was similar to that cited in the 2011 meta-analysis [7]. The acute respiratory distress aetiology was also different, showing a high (90\%) prevalence of obstructive airways disease (bronchiolitis, obstructive bronchitis, asthma, croup and nasal obstruction) in Switzerland and, compared with Switzerland, a higher (41\%) prevalence of parenchymal 
Table 3. Predictors of clinical hypoxaemia in children aged 2 months to 5 years with acute respiratory distress, uni- and multivariate analysis.

\begin{tabular}{|c|c|c|c|c|c|}
\hline Parameters and signs & Prevalence, \% & Sensitivity, \% (95\% Cl) & Specificity, \% (95\% Cl) & DOR (95\% CI) & aDOR $(95 \% \mathrm{Cl})$ \\
\hline $\mathrm{RR} \geq 60 \mathrm{bpm}$ & $13(12)$ & $0.20(0.12-0.28)$ & $0.90(0.84-0.96)$ & $2.22(0.61-8.11)$ & \\
\hline Temperature $\geq 37.5^{\circ} \mathrm{C}$ & $44(39)$ & $0.57(0.48-0.66)$ & $0.63(0.57-0.72)$ & $2.26(0.73-7.03)$ & \\
\hline Poor general status & $49(44)$ & $0.71(0.63-0.80)$ & $0.60(0.51-0.69)$ & 3.72 (1.09-12.70) & $1.71(0.35-8.25)$ \\
\hline Abnormal alertness & $28(25)$ & $0.57(0.48-0.66)$ & $0.79(0.72-0.87)$ & $5.13(1.60-16.49)$ & $3.32(0.67-16.41)$ \\
\hline Restlessness & $28(25)$ & $0.36(0.27-0.45)$ & $0.76(0.68-0.84)$ & $1.79(0.54-5.87)$ & \\
\hline Inability to feed/drink & $31(28)$ & $0.50(0.41-0.59)$ & $0.75(0.67-0.83)$ & $3.00(0.95-9.43)$ & $1.18(0.28-5.05)$ \\
\hline Cyanosis & $15(13)$ & $0.64(0.55-0.73)$ & $0.94(0.89-0.98)$ & $27.30(6.94-107.46)$ & $27.67 *(4.55-168.27)$ \\
\hline Grunting & $19(17)$ & $0.21(0.14-0.29)$ & $0.84(0.77-0.90)$ & $1.38(0.35-5.51)$ & \\
\hline Nasal flaring & $52(46)$ & $0.71(0.63-0.80)$ & $0.57(0.47-0.66)$ & $3.27(0.96-11.17)$ & $1.57(0.34-7.06)$ \\
\hline Head nodding & $22(20)$ & $0.50(0.41-0.59)$ & $0.85(0.78-0.91)$ & $5.47(1.67-17.85)$ & $0.77(0.12-4.95)$ \\
\hline Supraclavicular retraction & $14(13)$ & $0.17(0.10-0.24)$ & $0.95(0.91-0.99)$ & $3.70(0.78-17.47)$ & $1(0.15-6.55)$ \\
\hline Intercostal retraction & $76(68)$ & $0.93(0.88-0.98)$ & $0.35(0.26-0.44)$ & $7.02(0.88-55.95)$ & $3.19(0.34-29.89)$ \\
\hline Subcostal retraction & $71(63)$ & $0.93(0.88-0.98)$ & $0.40(0.30-0.49)$ & $8.52(1.07-67.82)$ & $4.25(0.38-47.3)$ \\
\hline Paradoxal breathing & $14(13)$ & $0.17(0.10-0.24)$ & $0.95(0.91-0.99)$ & $4.11(0.87-19.37)$ & $1.85(0.35-9.78)$ \\
\hline Crackles & $40(36)$ & $0.57(0.48-0.66)$ & $0.67(0.58-0.75)$ & $2.67(0.85-8.34)$ & \\
\hline Wheeze (with stethoscope) & $38(34)$ & $0.43(0.34-0.52)$ & $0.67(0.58-0.76)$ & $1.52(0.49-4.76)$ & \\
\hline $\begin{array}{l}\text { Wheezing (without stetho- } \\
\text { scope) }\end{array}$ & $45(40)$ & $0.36(0.27-0.45)$ & $0.58(0.49-0.68)$ & $0.78(0.24-2.50)$ & \\
\hline
\end{tabular}

Notes: DOR, diagnostic odds ratio; aDOR, adjusted diagnostic odds ratio after multiple logistic regression; ${ }^{*} p<0.05 ; 95 \% \mathrm{Cl}$, confidence interval of $95 \%$; RR, respiratory rate.

Bold values are significant values.

Table 4. Models of combinations of signs and their diagnostic accuracy in predicting hypoxaemia among children from 2 months to 5 years of age with acute respiratory distress.

\begin{tabular}{|c|c|c|c|}
\hline Models & $\begin{array}{c}\text { Sensitivity (95\% } \\
\text { CI) }\end{array}$ & $\begin{array}{l}\text { Specificity (95\% } \\
\text { CI) }\end{array}$ & DOR $(95 \% \mathrm{Cl})$ \\
\hline $\begin{array}{l}\text { WHO model when oxygen's supply is scarce [6]: central cyanosis, or inability to } \\
\text { drink or to feed }\end{array}$ & $0.79(0.71-0.86)$ & $0.75(0.67-0.83)$ & $11.15(2.87-43.34)$ \\
\hline $\begin{array}{l}\text { WHO model when oxygen's supply is ample [6]: central cyanosis, or inability to } \\
\text { drink or to feed, or severe chest indrawing, or RR 70/min, or restlessness or } \\
\text { grunting }\end{array}$ & $0.93(0.88-0.98)$ & $0.60(0.51-0.69)$ & $19.33(2.43-153.8)$ \\
\hline $\begin{array}{l}\text { WHO modified by Weber et al. [12]: inability to feed/drink, or cyanosis, or RR 70/ } \\
\text { min, or severe chest retraction }\end{array}$ & $0.86(0.79-0.92)$ & $0.51(0.41-0.60)$ & $6.13(1.30-28.83)$ \\
\hline $\begin{array}{l}\text { WHO modified by Weber et al. [12]: inability to feed/drink, or cyanosis, or severe } \\
\text { chest retraction }\end{array}$ & $0.86(0.79-0.92)$ & $0.51(0.41-0.60)$ & $6.13(1.30-28.83)$ \\
\hline Onyango et al. [10]:RR 70/min, or grunting, or chest retraction (age $<12$ months) & $0.29(0.20-0.37)$ & $0.69(0.60-0.78)$ & $0.89(0.26-3.08)$ \\
\hline Dyke et al. [11]: grunting, or RR 90/min, or cyanosis, or reduced consciousness & $0.79(0.71-0.86)$ & $0.70(0.62-0.79)$ & $8.60(2.23-33.12)$ \\
\hline Usen et al. [2]: cyanosis, or head nodding & $0.64(0.55-0.73)$ & $0.77(0.70-0.85)$ & $6.14(1.86-20.21)$ \\
\hline $\begin{array}{l}\text { Lodha et al. [13]: tachypnoea (RR } 60,50 \text { and } 40 / \text { min for age }<3 \text { months, } \\
3-12 \text { months, and }>12 \text { months, respectively), or lower chest retraction, or } \\
\text { crackles }\end{array}$ & $0.93(0.88-0.98)$ & $0.21(0.13-0.28)$ & $3.42(0.42-27.74)$ \\
\hline $\begin{array}{l}\text { Lodha et al. [13]: Lodha et al.: tachypnoea (RR } 70,60 \text { and } 50 / \text { min for age } \\
<3 \text { months, 3-12 months, and }>12 \text { months, respectively), or lower chest } \\
\text { retraction }\end{array}$ & $0.93(0.88-0.98)$ & $0.31(0.23-0.40)$ & $5.91(0.74-47.26)$ \\
\hline $\begin{array}{l}\text { Lodha et al. [13]: Lodha et al.: tachypnoea (RR } 80,70 \text { and } 60 / \text { min for age }<3 \\
\text { months, } 3-12 \text { months, and }>12 \text { months, respectively), or lower chest retraction }\end{array}$ & $0.93(0.88-0.98)$ & $0.40(0.30-0.49)$ & $8.52(1.07-67.82)$ \\
\hline $\begin{array}{l}\text { Lodha et al. [13]: Lodha et al.: tachypnoea (RR } 80,70 \text { and } 60 / \mathrm{min} \text { for age }<3 \\
\text { months, 3-12 months, and }>12 \text { months, respectively), crackles, or wheeze (with } \\
\text { stethoscope) }\end{array}$ & $0.79(0.71-0.86)$ & $0.44(0.34-0.53)$ & $2.85(0.75-10.88)$ \\
\hline
\end{tabular}

Notes: DOR, diagnostic odds ratio; $95 \% \mathrm{Cl}$, confidence interval of $95 \%$; $\mathrm{RR}$, respiratory rate.

Bold values are significant values.

disease (pneumonia, pleural effusion and tuberculosis) in Senegal. Hypoxaemia was less common in patients presenting with obstructive airways disease than in those presenting another aetiology (parenchymatous or systemic). Moreover, wheezing, an obstruction-specific sign, was the only clinical sign associated with a reduction of the post-test hypoxaemia probability, though not statistically significant. In this study, the data were treated as a whole, and centre-specific analysis was not performed because of the small number of included patients.

Some methodological limitations should be mentioned. Firstly, in three of the four hospitals not all the physicians working in the emergency unit were enrolling patients. Therefore, according to the inclusion criteria, not all eligible patients were enrolled in the study. Thus, selection bias is a possibility and the prevalence of hypoxaemia could be distorted. The calculated prevalence is, nevertheless, similar to that in the meta-analysis [7]. Secondly, the assessment of clinical signs always depends on the perception, interpretation and judgement of individual physicians. We tried to reduce this subjectivity as much as possible by providing the most detailed description possible for each clinical sign in the questionnaire, but grunting, for example, was surprisingly less prevalent in this study than in the literature. 
These results combined with the findings of the meta-analysis [7] suggest that, to ensure the treatment of all hypoxaemic children and to avoid wasting concentrated oxygen, the diagnosis of hypoxaemia in children aged 2 months to 5 years with acute respiratory distress should not be based on one clinical sign alone and not even on a combination of clinical signs. However, pulse oximetry is, regrettably, expensive and generates ongoing maintenance costs. Its use is, therefore, not widespread in resource-limited settings. Physicians in small- and medium-sized hospitals in low-income countries have to rely on clinical signs to identify hypoxaemic patients. As hypoxaemia may have serious consequences if oxygen is not given and oxygen therapy has almost no adverse effects, an adequate test for detecting hypoxaemia should have a high sensitivity and reasonable specificity. The only model that fits these criteria is the WHO guideline for when there is ample oxygen supply. It dictates that oxygen should be given to children with central cyanosis, inability to drink or to feed, severe chest indrawing, respiratory rate $\geq 70$ breaths/min, grunting with every breath (in young infants) or those who display head nodding [6]. In conclusion, hypoxaemia can be excluded in a patient if no signs included in the model are displayed. Unfortunately, many non-hypoxaemic patients would receive oxygen and this leads to wasting concentrated oxygen, a sometimes rare and expensive resource.

These results can easily be generalised to all children aged 2 months to 5 years presenting at emergency units with acute respiratory distress because the four hospitals had very different characteristics (poor- and rich-resource settings, specialised and non-specialised emergency units) and children with all acute respiratory distress aetiologies were included.

Given the relatively low specificity of the WHO model when oxygen supply is ample, further prospective studies are required to elaborate and validate more effective models for predicting hypoxaemia in children aged 2 months to 5 years with acute respiratory distress in emergency units. We suggest that new models should also include signs with a high diagnostic odds ratio such as cyanosis, subcostal and intercostal retractions, head nodding, abnormal alertness and paradoxal breathing.

Trial registration number: CER-VD, P 456/15

\section{Acknowledgements}

The authors gratefully acknowledge the hard work and dedication of the physician at each site who collected data and instructed other physicians to enrol patients. We are very grateful to the physicians who enrolled and cared for the study patients in the study, and to the patients' guardians who agreed to participate and made the study possible.

\section{Disclosure statement}

No potential conflict of interest was reported by the authors.

\section{Notes on contributors}

Lucie von der Weid, Medical Doctor, worked in pediatrics in the hospital of Nyon (Switzerland) and in the hospital of Pikine (Senegal), and currently works in the children hospital in Lausanne (Switzerland).

Mario Gehri is the Head doctor and in charge of the children hospital of Lausanne (Switzerland).

Boubacar Camara is the Head doctor, in charge of the paediatric department in the hospital of Pikine (Dakar, Senegal).

Aliou Thiongane is an assistant professor in the Albert-Royer children hospital (Dakar, Senegal).

Andres Pascual is the Head doctor and in charge of the paediatric department in the hospital of Nyon (Switzerland).

Jean-Yves Pauchard is an assistant professor in the children hospital of Lausanne (Switzerland).

\section{References}

[1] World Health Organization. Pneumonia fact sheet; 2015 Nov. Available from: http://www.who.int/mediacentre/ factsheets/fs331/en/

[2] Usen S, Weber M, Mulholland K, et al. Clinical predictors of hypoxaemia in Gambian children with acute lower respiratory tract infection: prospective cohort study. $\mathrm{Br}$ Med J. 1999;318:86-91.

[3] Duke T, Mgone J, Frank D. Hypoxaemia in children with severe pneumonia in Papua New Guinea. Int J Tuberc Lung Dis. 2001;5:511-519.

[4] Duke $T$, Wandi $F$, Jonathan $M$, et al. Improved oxygen systems for childhood pneumonia: a multihospital effectiveness study in Papua New Guinea. Lancet. 2008;372:1328-1333.

[5] Lee WW, Mayberry K, Crapo R, et al. The accuracy of pulse oximetry in the emergency department. Am J Emerg Med. 2000;18:427-431.

[6] World Health Organization. Pocket book of hospital care for children: guidelines for the management of common illnesses with limited resources. Geneva: WHO; 2005. Chapter 10.7, Oxygen therapy; p. 281.

[7] Zhang L, Mendoza-Sassi R, Santos JC, et al. Accuracy of symptoms and signs in predicting hypoxaemia among young children with acute respiratory infection: a metaanalysis. Int J Tuberc Lung Dis. 2011;15:317-325.

[8] Szilagyi P. Techniques of examination. In: Bickley S, editor. Bates' guide to physical examination and history taking. 8th ed. Philadelphia (PA): Wolters Kluwer Health; 1998. p. 686-689.

[9] World Health Organization. Oxygen therapy for acute respiratory infections in young children in developing countries; 1993. Available from: http://www.who.int/ maternal_child_adolescent/documents/ari_93_28/en/

[10] Onyango FE, Steinhoff MC, Wafula EM, et al. Hypoxaemia in young Kenyan children with acute lower respiratory infection. Br Med J. 1993;306:612-615.

[11] Dyke T, Lewis D, Heegaard W, et al. Predicting hypoxia in children with acute lower respiratory infection: a study in the highlands of Papua New Guinea. J Trop Pediatr. 1995;41:196-201. 
[12] Weber M, Usen W. Clinical signs of hypoxaemia in children with acute lower respiratory infection: indicators of oxygen therapy. Int J Tuberc Lung Dis. 2001;5:505-510.

[13] Lodha R, Bhadauria PS, Kuttikat AV, et al. Can clinical symptoms or signs accurately predict hypoxaemia in children with acute lower respiratory tract infections? Indian Pediatr. 2004;41:129-135.

[14] Lozano M, Steinhoff M, Ruiz JG, et al. Clinical predictors of acute radiological pneumonia and hypoxaemia at high altitude. Arch Dis Child. 1994;71:323-327.

[15] Wandeler G, Pauchard JY, Zangger E, et al. Which clinical signs predict hypoxaemia in young Senegalese children with acute lower respiratory tract disease? Paediatr Int Child Health. 2015;35:65-68.

[16] Bassat Q, Lanaspa M, Machevo S, et al. Hypoxaemia in Mozambican children $<5$ years of age admitted to hospital with clinical severe pneumonia: clinical features and performance of predictor models. Trop Med Int Health. 2016;21:1147-1156.
[17] Reuland DS, Steinhoff MC, Gilman RH, et al. Prevalence and prediction of hypoxemia in children with respiratory infections in the Peruvian Andes. J Pediatr. 1991;119:900906.

[18] O'Dempsey TJ, Todd JE. Chest infections in African children. Respiratory rate poor predictor of hypoxaemia. Br Med J. 1993;306:1342.

[19] Singhi S, Deeo A, Kaur H. Prevalence and predictors of hypoxaemia in acute respiratory infections presenting to pediatric emergency department. Indian J Crit Care Med. 2003;7:118-123.

[20] Laman M, Ripa P, Vince J, et al. Can clinical signs predict hypoxemia in Papua New Guinean children with moderate and severe pneumonia? J Trop Pediatr. 2006;25:23-27.

[21] Basnet S, Adhikari RK, Gurung CK. Hypoxemia in children with pneumonia and its clinical predictors. Indian J Pediatr. 2006;73:777-781. 
Appendix 1. Specificity and sensitivity of clinical signs of hypoxaemia ( $\square$ specificity, $\triangle$ sensitivity).

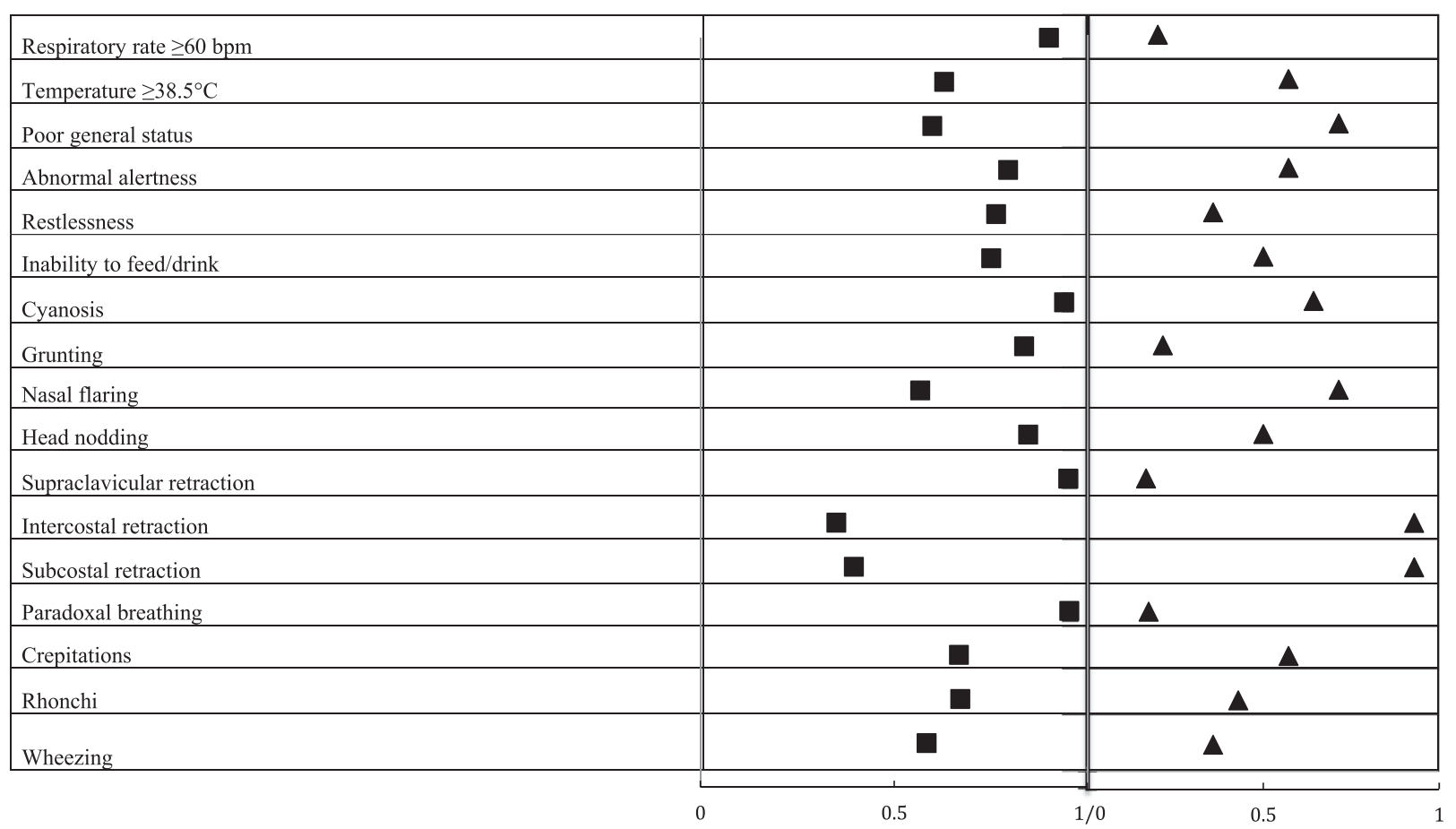

\section{Appendix 2. Specificity and sensitivity of combinations of signs. ( $\square$ specificity, $\Delta$ sensitivity, RR, respiratory rate).}

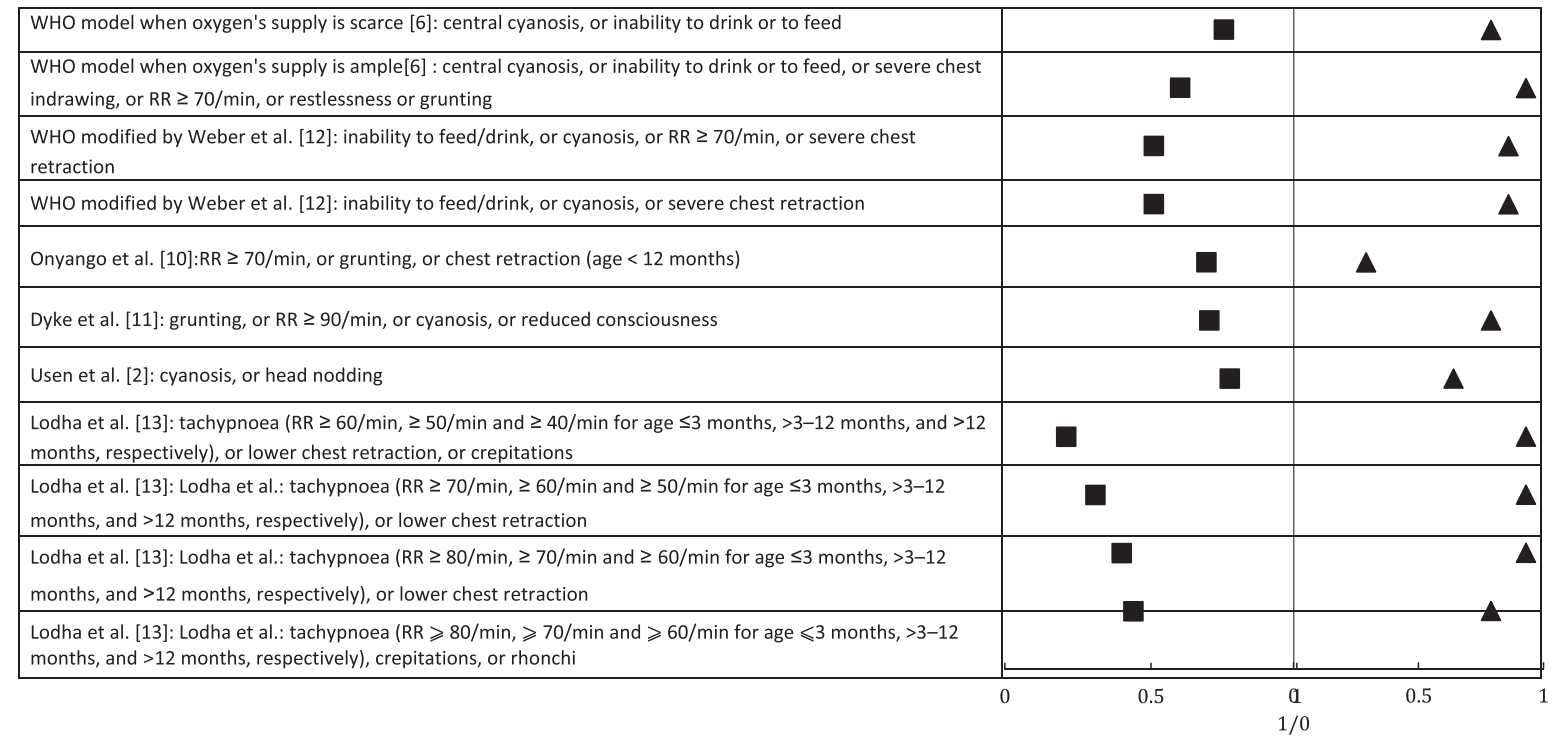




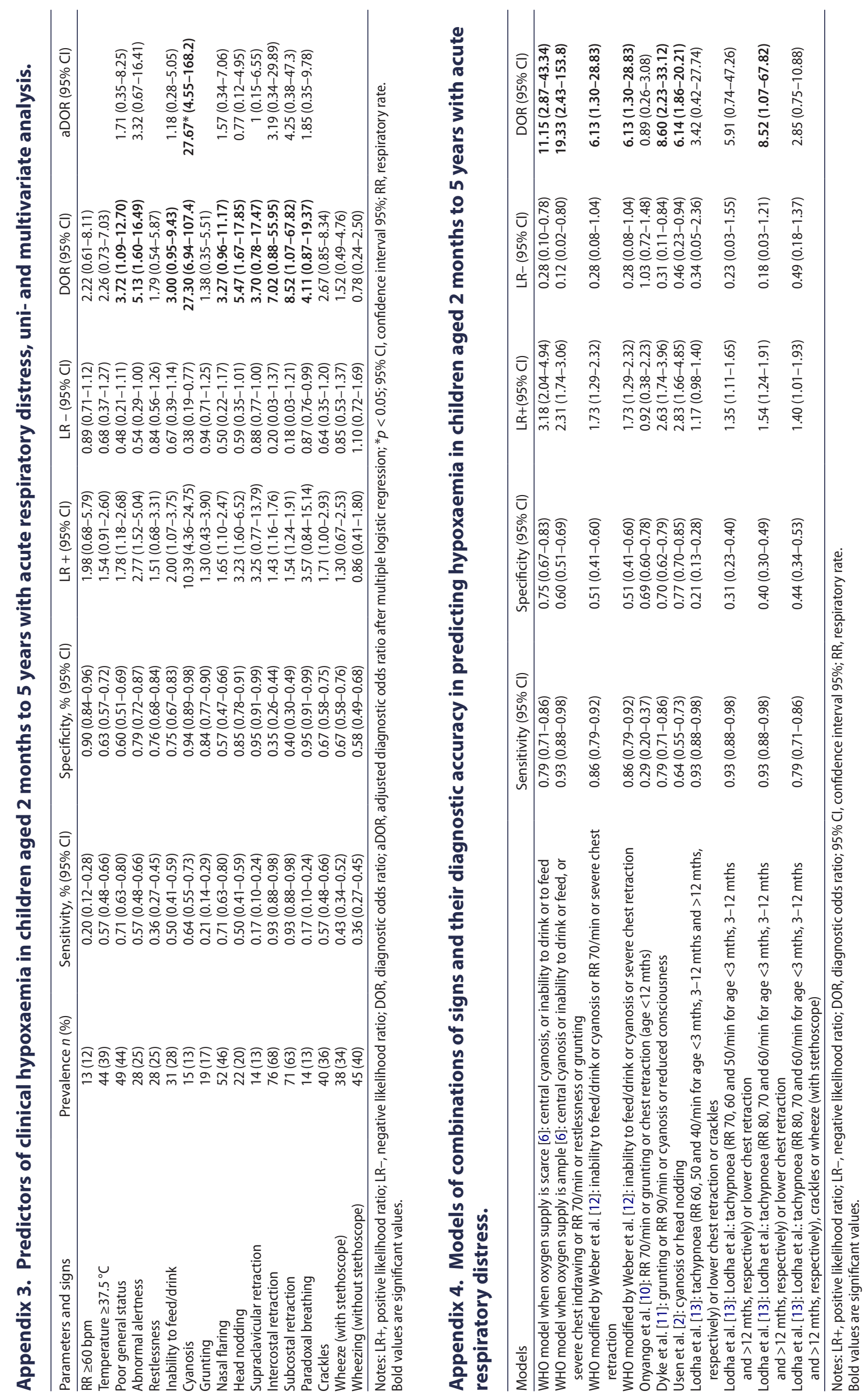

